\title{
Overview on plasma operation with a full tungsten wall in ASDEX Upgrade
}

\author{
R. Neu ${ }^{a *}$, A. Kallenbach ${ }^{a}$, M. Balden ${ }^{a}$, V. Bobkov ${ }^{a}$, J.W. Coenen ${ }^{b}$,

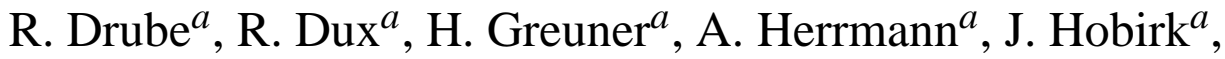

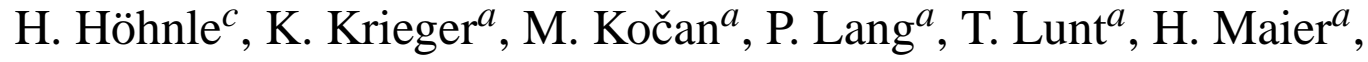

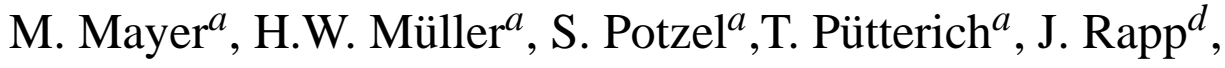 \\ V. Rohde ${ }^{a}$, F. Ryter ${ }^{a}$, P.A. Schneider ${ }^{a}$, J. Schweinzer $^{a}$, M. Sertoli ${ }^{a}$, \\ J. Stober ${ }^{a}$, W. Suttrop ${ }^{a}$, K. Sugiyama ${ }^{a}$, G. van Rooij ${ }^{e}$,

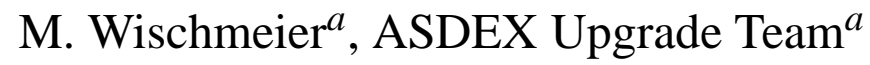 \\ ${ }^{a}$ Max-Planck-Institut für Plasmaphysik, EURATOM-Association, D-85748 Garching, \\ Germany \\ ${ }^{b}$ Institut für Energie- und Klimaforschung IV, Forschungszentrum Jülich, TEC, \\ Association EURATOM-FZJ, D-52425 Jülich, Germany \\ ${ }^{c}$ Institut für Plasmaforschung, Universität Stuttgart, Stuttgart, Germany \\ ${ }^{d}$ Oak Ridge National Laboratory, Oak Ridge, Tennessee, USA \\ e FOM-Institute for Plasma Physics Rijnhuizen, Assoc. Euratom-FOM, Trilateral Euregio \\ Cluster, 3430 BE, Nieuwegein, The Netherlands
}

\begin{abstract}
Operation with all tungsten plasma facing components has become routine in ASDEX Upgrade. The conditioning of the device is strongly simplified and short glow discharges are used only on a daily basis. The long term fuel retention was reduced by more than a factor of 5 as demonstrated in gas balance as well as in post mortem analyses. Injecting nitrogen
\end{abstract}


for radiative cooling, discharges with additional heating power up to $23 \mathrm{MW}$ have been achieved, providing good confinement $\left(\mathrm{H} 98_{y 2}=1\right)$, divertor power loads around $5 \mathrm{MW}$ $\mathrm{m}^{-2}$ and divertor temperatures below $10 \mathrm{eV}$. ELM mitigation by pellet ELM pacemaking or magnetic perturbation coils reduces the deposited energy during ELMs, but also keeps the $\mathrm{W}$ density at the pedestal low. As a recipe to keep the central $\mathrm{W}$ concentration sufficiently low, central (wave) heating is well established and low density H-Modes could be re-established with the newly available ECRH power of up to $4 \mathrm{MW}$. The ICRH induced W sources could be strongly reduced by applying boron coatings to the poloidal guard limiters.

PSI-20 keywords:

Tungsten, Impurity, Retention, Boron, ASDEX Upgrade

PACS numbers:

52.25.Vy, 52.40.Hf, 52.55.Rk, 52.55.Fa

* Corresponding author address: Boltzmannstr.2 85748 Garching

* Corresponding author E-mail: Rudolf.Neu@ipp.mpg.de

Presenting author: Rudolf Neu

Presenting author e-mail: Rudolf.Neu@ipp.mpg.de

\section{Introduction}

Tungsten is the top candidate for the plasma facing material (PFM) in future fusion reactors, due to its capability to survive in high temperature, high neutron irradiation environment, combined with a low hydrogen retention [1] (and references therein). However, due to its strong ability to hamper plasma operation by central radiation and the very beneficial behaviour of carbon based plasma facing components (PFCs), only a few devices have used it as plasma facing material re- 
cently [2]. Also ASDEX Upgrade (AUG) applied W very cautiously and only two rows of $\mathrm{W}$ coated graphite tiles were installed in the main chamber at the central column in 1999. This part was identified to allow first investigations with $\mathrm{W}$ plasma facing components (PFCs) in the main chamber, but was also considered not to hamper the usual operation [3]. Previously, in 1996, the strike point area was equipped with $\mathrm{W}$ coated tiles, demonstrating that the use of tungsten is feasible in a divertor tokamak. At the same time strong carbon deposition at the inner divertor was observed making evident that the main chamber carbon PFCs are a significant source of impurities [4,5]. After encouraging results, the area of $\mathrm{W}$ components was continuously increased until finally in 2007 100\% W coverage was reached [6], representing the only full tungsten fusion device. Meanwhile, operation with all W PFCs has become routine in ASDEX Upgrade and several tools have been developed to avoid or mitigate the negative effects of $\mathrm{W}$ in the discharges. The step by step approach pursued in the implementation of the W PFCs not only allowed to identify the role of different local $\mathrm{W}$ sources for the $\mathrm{W}$ density in the plasma and to investigate the effect of mixed materials, but also to adjust the operational procedures to a narrowing operational space.

With the new ITER-Like Wall (ILW) coming alive in JET [7,8], using W as PFM in the divertor and $\mathrm{Be}$ in the main chamber, some issues ask for revisiting of the AUG data. This contribution intends not only to highlight some of the major achievements of the $\mathrm{W}$ programme in AUG but it will also present details of the operational experiences and new investigations which were triggered by recent results achieved in JET.

\section{Conditioning and Plasma Behaviour}

Tungsten coatings on fine grain graphite have been used in ASDEX Upgrade in order to provide a solution which complies with the technical boundary conditions when transforming from C to W PFCs. After trials with VPS $(200 \mu \mathrm{m} \mathrm{W})$ coatings, 
which delaminated after local thermal overloading, all coatings were produced by physical vapour deposition with thicknesses of up to $4 \mu \mathrm{m}$ in the main chamber and with $10 \mu \mathrm{m} \mathrm{W}$ on a $3 \mu \mathrm{m}$ Mo interlayer, similar to the one adopted for the JET ITER-Like Wall project [9], for the limiters and the divertor. For more details on the coatings the reader should refer to [10] and references therein. Fig. 1 shows the interior of ASDEX Upgrade early in 2012. To protect the coatings from overloading a realtime protection circuit was implemented based on CCD cameras, allowing a rapid shut down of the auxiliary heating systems and the discharge [11]. After the finalization of the full $\mathrm{W}$ wall, almost two experimental campaigns were operated with new/cleaned W surfaces and without boronisation, comprising four restarts after vents. Besides oxygen, carbon still was observed in the plasma with concentrations in the range of $1 \%$. The carbon source is still not conclusively identified, but chemical erosion by $\mathrm{D}$ and $\mathrm{O}$ from old co-deposits on the stainless steel vacuum vessel wall is seen as a strong candidate [12]. Despite these initially high levels of low-Z impurities a quick recovery of the full $\mathrm{W}$ device could be achieved using an optimised start-up sequence. ECRH is added quite early in the discharge to increase the electron temperature and thereby the conductivity, without increasing the density to stay well below the Greenwald density limit. NBI is added from $0.3 \mathrm{~s}$ on to increase further the available heating power. In the last of these restarts (in 2008) only 5 discharges were needed to reach the pre-programmed current flattop and only four more to achieve the first H-Mode transition [10]. Even more, the reproducibility of break-down and subsequent current ramp-up is considerably improved with $\mathrm{W}$ as plasma facing material, which is exemplified by the fact that inter-discharge glow discharge cleaning is not necessary anymore and usually only a few minutes of deuterium glow are done at the start of a session. After boronisation the oxygen and carbon concentration experienced a strong reduction $(\mathrm{C}$ : factor 10 , down to $0.15 \%$, O: factor 4 , down to $0.02 \%$ ). Whereas the oxygen stayed low and was even reduced more after subsequent boronisations, carbon returned to about half the pre-boronisation level after about 30-40 discharges. Since in earlier campaigns boronisations were performed regularly, the later $\mathrm{C}$ concentration 
$(\approx 0.8 \%)$ has to be taken as reference for the comparison. In parallel to the strong reduction of low-Z impurities, a factor of 2 increase of the peak power load in the divertor was observed, eventually leading to the delamination of the thick VPS coatings as already stated above [13].

The conditioning of the device was monitored by a daily performed 'standard' discharge, which allowed also to monitor the long term evolution of confinement and L-H threshold [14]. Unfortunately, this discharge type could not be performed in the first campaign after the implementation of the full $\mathrm{W}$ wall, because of a damaged flywheel generator and resulting constraints on the power supply. From 2008 the L-H transition was again checked regularly. As can be judged from Fig. 2, there is clear evidence, that the L-H threshold is reduced by $25 \%$ in the discharges under consideration, which are performed at $I_{p}=1 \mathrm{MA}, B_{t}=2.5 \mathrm{~T}$ and at a line averaged density $n_{e} \approx 5 \cdot 10^{19} \mathrm{~m}^{-3}$. The threshold power $(d W / d t$ is subtracted from the absorbed heating power) is scaled to the ITER H-mode power threshold scaling [15]. It has to be noted in addition that the scatter in the threshold power seems to be slightly reduced, again reflecting the less varying conditioning with the full $\mathrm{W}$ wall.

Triggered by the observation of lower pedestal temperatures at a given current, density and heating power with the JET ILW [8], the pedestal values with the W wall were compared to those under similar discharge conditions in a carbon dominated AUG. This turned out to be non-trivial, because typically the discharges run with the $\mathrm{W}$ wall are performed at higher gas puffing levels to avoid too large $\mathrm{W}$-influx and the heating mix was changed to preferentially ECRH instead of ICRH (see Sec. 4). Nevertheless, almost matching discharges at $I_{p}=1 \mathrm{MA}, B_{t}=2.4-2.5 \mathrm{~T}$, could be identified which were heated predominantly by NBI with additional $3 \mathrm{MW}$ of ICRH (C dominated) or 1.5 MW of ECRH (full W wall). Figure 3 shows the values of the plasma parameters at the pedestal top together with the corresponding $\mathrm{H}$ factors. Similar to JET the pedestal temperatures are indeed lower, but at the same time the densities are higher resulting in a very similar pressure at the pedestal top, increasing monotonically with the applied additional heating. The reason for the 
higher density is not clear and it can only be speculated that a different recycling (for example the higher energy reflection coefficient) on tungsten PFCs compared to carbon based PFCs could play a role. The H-factor remains also mainly unchanged differently to the observation in JET [8]- the two points at higher H-factors found for the $\mathrm{C}$ dominated case hint obviously to an improved central confinement.

\section{Retention of Gases}

One of the main goals of the implementation of the $\mathrm{W}$ walls in AUG was to check the predictions from laboratory experiments on the hydrogen retention in W. Quite some effort was invested in performing gas balance experiments and in post mortem analyses of retrieved samples and tiles. A clear reduction by a factor of 5 was found in both kind of investigations compared to operation in C dominated AUG [16,17]. This reduction in retention is less than what is projected for ITER, but it is in line with the assumptions used for those calculations [18]. Specifically, AUG is typically operated at lower surface temperatures than that expected in ITER $[18,19]$ which leads to a higher H-retention in W. Furthermore, the all-W AUG still has carbon in the machine [20], which is not accounted for in the all-W predictions, and finally, the H-fluence at the strike point during one campaign in AUG is smaller than for one full power discharge in ITER. The dependence of H-retention with fully-C and fully-W PFCs on fluence is linear for carbon PFCs (mainly $\mathrm{H}$ co-deposition with C), whereas with tungsten PFCs (H diffusion in $\mathrm{W}$ ), it increases only with about the square-root of the H-fluence $[18,19]$ or it even saturates, depending on the assumptions on the role of neutron damage [21]. Post mortem measurements of the deuterium content in the coatings and the bulk-W Langmuir probes [17] at the outer divertor strike-point and the latest investigations using bulk W-samples exposed in AUG with the divertor manipulator [22] show that the retained deuterium is in line with that measured in laboratory experiments on which the predictions

for ITER are based [19]. For a campaign integrated D-fluence of $\approx 5 \cdot 10^{25} \mathrm{~m}^{-2}$ 
the retained deuterium was about $10^{22} \mathrm{~m}^{-2}$. Investigations of exposed polished $\mathrm{W}$ samples reveal the formation of blisters which were not yet found on 'technical' surfaces, which leads to the conclusion that they will not strongly enhance the Hretention [23].

At the inner divertor, which usually is deposition dominated, still deuterium retained in co-deposits with $\mathrm{C}$ was found in the first full $\mathrm{W}$ campaign [20], although the area of main (co-)deposition shifted away from the strikepoint towards the private flux region. Typically, the observed $\mathrm{D} / \mathrm{C}$ ratio in the $\mathrm{C}$ deposits is $0.2-0.4$ and the campaign averaged deuterium deposition rate was reduced from $\approx 5 \cdot 10^{19}$ $\mathrm{m}^{-2} \mathrm{~s}^{-1}$ in the carbon dominated AUG to $\approx 1 \cdot 10^{19} \mathrm{~m}^{-2} \mathrm{~s}^{-1}$ in the full W AUG. The source of the residual carbon could not be identified unambiguously, but potential candidates are old $\mathrm{C}$ layer on the stainless steel vacuum vessel, $\mathrm{C}$ eroded from the tile sides and backs as well as $\mathrm{C}$ impurities in the $\mathrm{W}$ coatings.

As in earlier investigations in AUG and other devices (see for example [24]), the absolute amount found to be retained in gas balance measurements is larger than the one found in the post mortem measurements. This is to some extent due to the larger measurement error, which is close to the value of the retained gas [25], but also the fact that the dynamic retention may not be accounted for precisely enough. Fig. 4 shows that depending on the puffing rate saturation of the wall is reached later in the discharge. Similarly, it is shown (in the insert) that the amount of gas needed to saturate the wall is similar in all cases, which means that in order to achieve robust results on a discharge resolved basis it has to be ensured that steady conditions are reached. On top of this it was found [26] that the major part of the dynamic inventory is only released with a decay time of about 200s, making long integration times necessary.

Besides H-retention the storage and release of other gas species is important for operational issues. As already stated above, inter-shot He glow was required in the carbon dominated AUG for reproducible discharge conditions. This procedure was continued even with increasing surface coverage with $\mathrm{W}$ without investigating whether He glow was still needed, or whether it was detrimental to operation. Even- 
tually it was discovered that the control of the density during current ramp-up got worse and a closer look showed that the He-content was permanently rising over long operational periods. Subsequent laboratory experiments revealed that indeed $\mathrm{W}$ has a large potential for He surface storage and release under particle bombardment [27]. In addition, a correlation of confinement degradation even with $\mathrm{He}$ concentrations below the $10 \%$ level was found. Measurements of the edge plasma profile suggested that this degradation is due to an eroded ion pedestal and the effect of profile stiffness [28]. This effect led to a complete abandoning of He glows during normal operations - without any detrimental effect on the conditioning [29]. As stated above, radiative cooling had to be employed in ASDEX Upgrade to keep the steady state power load at an acceptable level below $10 \mathrm{MWm}^{-2}$ in high power discharges at least shortly after a boronisation. As it turned out, puffing $\mathrm{N}_{2}$ is a very good substitute for intrinsic carbon in the full W AUG (see also below), differently to earlier experience in AUG, where the noble gases, Ar and Ne, were preferred for radiative scenarios [30] because there were easier to control in the presence of $\mathrm{C}$ PFCs. Since nitrogen shows some chemistry with W, laboratory investigations were performed which revealed the production of $\mathrm{WN}$ in the implantation region which saturates and is released at temperatures below $800 \mathrm{~K}$ [31]. The storage and release of nitrogen is also visible in AUG plasma discharges leading to an initial build up after which less nitrogen injection is needed to cause the same radiative cooling in the plasma, making a feedback controlled $\mathrm{N}_{2}$-puffing necessary. The nitrogen is stored only in the first few nanometres of the surface, resulting in surface area densities of about $10^{20}-10^{21} \mathrm{~m}^{-2} \mathrm{~s}$ and consequently in inventories below $10^{21}$ nitrogen atoms. When comparing this number to typical puffing rates of $5 \cdot 10^{21}$ $\mathrm{s}^{-1}$ it can be concluded that there is enough headroom for radiation control even with saturated walls. After switching off the $\mathrm{N}_{2}$ injection a few more discharges are needed to remove $\mathrm{N}$ from the surfaces [32]. Very recent investigation of the exhaust gas reveal that obviously the production of ammonia is significant. This can impact fuel retention experiments as well as it may be important for the layout of the tritium plant in ITER [33]. 


\section{Tungsten Sources and Transport}

\subsection{W Sources}

The time resolved $\mathrm{W}$ influx is obtained spectroscopically by measuring the WI line radiation at $400.9 \mathrm{~nm}$ using about 40 lines-of-sight covering the outboard divertor, some low field side guard and ICRH antenna limiters as well as the central column [34]. The measured photon flux density is transformed into an eroded tungsten flux density using the inverse photon efficiency, i.e. the $S / X B \approx 20$ (at $T_{e}^{d i v} \approx 10 \mathrm{eV}$ ) [35]. The divertor $\mathrm{W}$ source depends strongly on the divertor plasma temperature and the erosion during ELMs accounts for a significant fraction (above 80\%) of the total $\mathrm{W}$ eroded, for low temperature divertor conditions. The erosion is found consistent with sputtering by low-Z impurities - either intrinsic or as a result of impurity seeding [34]. During type III ELMy discharges, achieved by very high levels of $\mathrm{D}_{2}\left(4 \cdot 10^{22} \mathrm{~s}^{-1}\right)$ and $\mathrm{N}_{2}\left(1.8 \cdot 10^{22} \mathrm{~s}^{-1}\right)$ the electron temperatures could be reduced below $10 \mathrm{eV}$ even during ELMs and a rather complete suppression of the $\mathrm{W}$ erosion could be achieved as shown in Fig. 5. The faint $\mathrm{W}$ influx observed $\left(<10^{18}\right.$ $\mathrm{m}^{-2} \mathrm{~s}^{-1}$ ) has to be compared with typical values during type I ELMs which are up to $10^{21} \mathrm{~m}^{-2} \mathrm{~s}^{-1}[32,34]$. The main chamber $\mathrm{W}$ influx mainly depends on the proximity to the W surfaces and a compromise between high field side (HFS) sources and low field side sources has to be found. Typically, the integrated fluxes from the LFS and HFS are similar in size for similar distances, but it is more beneficial to have the LFS gap 1-2 centimetres larger than the HFS gap to reach the lowest $\mathrm{W}$ content [34]. Obviously, the low field side penetration of $\mathrm{W}$ is higher as also seen in Alcator C-Mod for molybdenum [36]. Comparing the absolute value of main chamber and divertor sources the time averaged divertor source is at least one order of magnitude larger in type I ELMy H-mode discharges without using ICRH $[34,10]$. During ICRH operation the limiter W source can approach the size of that in the divertor. This increase can be explained by an increased sheath potential in front of the antennas reaching a few tens of $\mathrm{eV}$ [34]. In order to reduce this 
W source antenna modelling was performed [37] and as a first step the limiting structures were modified to reduce the parallel electrical field at the antenna edge. By this procedure some reduction of the $\mathrm{W}$ release was found, although the effect was moderate due to the fact that only one out of 4 antennas was modified [38]. For the 2012 campaign the poloidal part of the limiters of two antennas were boron coated to reduce the $\mathrm{W}$ source ICRH without introducing $\mathrm{C}$ surfaces or other new materials (see Fig. 1). The coatings were produced by VPS on fine grain graphite similar as it was done in Alcator C-Mod for the molybdenum antenna limiters. This measure is seen as a workaround until new antennas with an improved design will be available (see Sec. 7). Fig. 6 shows a substantial reduction of the incremental W concentration (see next section) during ICRH which demonstrates that in the case of ASDEX Upgrade the antenna limiters are the most relevant source of $\mathrm{W}$ during ICRH operation.

\subsection{W transport and content}

The $\mathrm{W}$ content in the plasma is to a large extent governed by its transport at the edge as well as in the very centre, which means that similar W-influxes can lead to drastically different $\mathrm{W}$ concentrations. A schematic view of the most relevant processes as currently seen is presented in Fig.7. They can be described as an interplay of neoclassical effects with turbulent processes and macroscopic transport events as ELMs or sawteeth (see for example $[39,40]$ ). If the W content is high enough it can even influence the transport in the background plasma by changing the electron temperature profile through the radiation losses. For keeping the overall $\mathrm{W}$ content in H-Modes low it is essential to provide an edge instability which regularly diminishes the large edge impurity density gradient due to neoclassical effects [41]. The flushing could be provided by natural or stimulated ELMs [42,34] or by a change in the edge transport by magnetic perturbation coils [2]. The central tungsten density is deduced from VUV and X-ray spectroscopy. In ASDEX Upgrade emissions around $5 \mathrm{~nm}$, containing the quasicontinuum emission from $\mathrm{W}^{27+}-\mathrm{W}^{35+}$ and sin- 
gle spectral lines arising from $\mathrm{W}^{39+}-\mathrm{W}^{45+}$ as well as the spectral line at 0.794 $\mathrm{nm}$ emitted from Ni-like $\mathrm{W}^{46+}$ are monitored [43]. These ionisation stages provide information on the $\mathrm{W}$ density in the electron temperature range of about $1-4 \mathrm{keV}$. Fig. 8 shows a series of similar discharges where the level of the deuterium puff was varied by a factor of ten. As can be seen, in the period from $2.5 \mathrm{~s}-2.8 \mathrm{~s}$ the ELM frequency reduces by up to a factor 2 when reducing the deuterium puff and at the same time the $\mathrm{W}$ density rises by a factor of 5 . At the same time carbon density increases only by a factor of two, demonstrating that the influx of $\mathrm{C}$ does not depend so critically on the edge plasma conditions. It is clear that by increasing the gas puff level not only the ELM frequency changes, but also the erosion source in the divertor during as well as in-between the ELMs. Furthermore there is a reduction of the ionisation length as well as an increase of the prompt redeposition of $\mathrm{W}^{+}$ions, calling for a consistent modelling, which is provided in [41]. In the frame of the ongoing melting experiments performed with dedicated melt probes in the divertor $[44,45]$ the divertor retention has been reassessed using the $3 \mathrm{D}$ transport code EMC-3 [46]. The observed divertor retention is in line with earlier experiments [47] and could be reproduced with the code. It has to be stated however, that the code predicts a very strong variation of the retention depending on the detailed location of the source in respect to the strike point position due to a delicate balance of forces acting on the parallel transport of $\mathrm{W}$.

Central peaking of $\mathrm{W}$ is predominantly found in $\mathrm{H}$ mode discharges without sawteeth or other beneficial $(m, n)=(1,1)$ activities which increase central transport. In extreme cases of peaking - called accumulation - the central $\mathrm{W}$ concentration can reach values which are more than 50 times larger than the edge density [48]. Such a strong accumulation can cause very high central energy losses and lead to hollow temperature profiles and a subsequent collapse of the discharge, where the confinement is strongly degraded. In parallel to the degradation of the energy confinement also the particle confinement is reduced which releases part of the tungsten content. This allows mostly a non-disruptive shut-down of the discharges. Dedicated investigations [49] led to the conclusion that the $\mathrm{W}$ accumulation is mainly driven 
by neoclassical transport.

It could be shown early in the $\mathrm{W}$ programme that central deposition of heating power is very beneficial in reducing the W-peaking $[50,48]$. This heating can be provided either by ICRH or ECRH and even the deposition profile of beams using different acceleration voltage [4] or injection geometry plays a role. The amount of necessary local heating depends delicately on the local $\mathrm{W}$ concentration itself which was tested in similar accumulating discharges with different timing of an ECRH heating pulse [51]. Similarly, there is a tradeoff between reducing the overall $\mathrm{W}$ density by gas puffing and the necessary central heating to prevent accumulation [42]. To date, no quantitative relation between the necessary local heating power per locally radiated power could be established. In more recent investigation the deposition of the ECRH was varied either by changing the toroidal magnetic field or by changing the launching angle of the mirror. It became evident that to act on the very sharp peaking of the $\mathrm{W}$ concentration, deposition inside or very close to the accumulation area is necessary [52]. Detailed transport investigations using tracer impurities show that the local heating leads to a strong increase of anomalous transport [53]. This could be further detailed in [54] where the Ar tracer transport was compared to quasi-linear gyro-kinetic simulations, which qualitatively reproduce the positive convection and its decreasing trend for radii outside the ECRH deposition radius. However, for the most central ECR-heated discharge analysed, the resulting strong positive (outward) convection is probably not of turbulent nature but could be caused by the strong MHD activity present within the $q=1$ surface. To some extent ICRH and ECRH are interchangeable for the suppression of central accumulation. Despite the additional $\mathrm{W}$-influx produced by ICRH the $\mathrm{W}$ profile is flattened albeit at the cost of a higher average W concentration. For low density discharges this often outweighs the benefit achieved by the flattening of the profile. 


\section{Scenario Integration}

In present day devices, plasma scenarios are often optimized to reach specific and often narrow goals. In ITER and even more in DEMO, plasma scenarios have to fulfil all boundary conditions simultaneously, meaning that optimized confinement properties (good energy confinement - moderate impurity confinement), acceptable steady state power loads and strongly mitigated ELMs have to be achieved simultaneously. As a common method to reduce the steady state power load in the divertor, gaseous impurities are injected [55]. In order to provide a flexible protection allowing also to cope with the legacy of nitrogen, the ELM filtered (thermo-)electric current into a divertor tile, has been proven to be a reliable feedback signal on AUG [32]. The additional impurities have an impact on erosion, especially on that of tungsten because of its high threshold for sputtering by hydrogen (see Sec. 4.1). The effective erosion flux will result from a delicate interplay between the increased flux of impurity ions and the reduction of sputtering yield due to the lowered divertor plasma temperature. As stated above, nitrogen is most commonly used in AUG because it has been shown to provide the best divertor cooling effect, while maintaining or even improving the energy confinement [52]. This is due to the fact that for typical divertor plasma parameters radiation cooling by nitrogen is more efficient than that by neon [55] and the resulting $\mathrm{N}$ radiation inside the separatrix is rather low compared to that of Ar, thereby not reducing the ELM frequency. In order to investigate whether the beneficial properties of the radiative cooling can be extrapolated to higher $P / R$-values (heating power over major radius), as they are expected in ITER, experiments at highest available auxiliary heating power were performed. Fig. 9 shows the discharge with the highest power applied in ASDEX Upgrade to date with the divertor temperature controlled at about $11 \mathrm{eV}$, which exhibits good confinement at very benign divertor power loads.

Recently, the operational space of $\mathrm{N}_{2}$ seeded plasmas has been enhanced incorporating also the improved $\mathrm{H}$-Mode regime, providing even higher $\mathrm{H}$-factors at a given density than have been achieved in the carbon dominated AUG [56]. Since 
this scenario relies mostly on high background plasma density, advanced heating schemes for ECRH have been applied successfully to either prevent from cut-off (O2-Mode) or to allow lowering the magnetic field (X3-Mode). With both schemes a similar beneficial behaviour as with the usual X2-Mode heating in respect to the suppression of $\mathrm{W}$ peaking could be achieved [57].

It has been shown earlier that pellet ELM pacemaking is consistent with radiative cooling scenarios allowing a reduction of both the steady state and the transient power loads [58]. Mitigation of ELMs by increasing the overall edge transport with edge magnetic field perturbations as pioneered by DIII-D [59] and JET [60], became also possible in AUG after the installation of magnetic perturbation coils at the low field side of AUG [61,62]. In all discharges with successful ELM mitigation the residual core tungsten concentration is at the same level or lower than in comparable type-I ELMy phases [2]. Combined with pellet fuelling, densities 50\% above the Greenwald density could be achieved in H-Mode discharges [63].

\section{Outlook}

In the near future (starting 2013) a new antenna design will be implemented, consisting of three straps with individually adjustably phasing, which reduces the parallel component of RF electrical field and thereby the rectified sheath and concomitantly the $\mathrm{W}$ erosion [64]. In the same period, bulk $\mathrm{W}$ tiles will be installed at the outer strike-point position in order to further increase the power handling capability of the divertor [65]. In parallel, the divertor geometry will be slightly changed to allow a higher conductance to the divertor cryopump. Prototypes of the bulk tiles have been successfully tested in the neutral beam test facility GLADIS with power density of up $30 \mathrm{MWm}^{-2}$ reaching temperatures of up to $3500 \mathrm{~K}$ [66]

. Together with the foreseen midterm upgrade of the ECRH capability up to 6$8 \mathrm{MW}$, these enhancement should provide a further widening of the operational space towards lower collisionalities and thereby allowing to assess central plasma 
parameters closer to those of ITER.

PWI related investigations will also benefit from the bulk W divertor tiles by using them to test different gap shapings and to perform post mortem fuel retentions studies. Further melt studies will be performed in the near future using the existing divertor manipulator $[44,45]$. These will be complemented by experiments with the revitalised $\mathrm{W}(\mathrm{CO})_{6}$ probe [47], to study the $\mathrm{W}$ penetration from the divertor and the main chamber. Together with the new divertor, also the divertor manipulator will be completely refurbished in 2013. The new design will allow the test not only of small probes but of complete PFCs which can be either actively cooled or heated, to provide defined conditions for exposure.

Together with the partly similar and partly complementary experiments at JET with its ILW even more conclusive answers on the behaviour of W as PFM can be expected in the near future.

\section{Conclusion}

Operation with W PFCs in the divertor and the main chamber has become routine in ASDEX Upgrade. During the last years many topics related to operation with W PFCs have been successfully addressed and precious experience for the operation of JET and futures devices have been gained.

Several start-ups were performed since then without any boronisation, proving that performance and confinement similar to boronised operation with carbon PFCs can be reached in high power, high density discharges. Even more, the reproducibility of break-down and subsequent current ramp-up is considerably improved with $\mathrm{W}$ as plasma facing material, which is exemplified by the fact that inter-discharge glow discharges cleaning is not necessary at all any more. Similarly the breakdown after disruptions is also facilitated by the $\mathrm{W}$ walls. Very recently very similar experience has been gained at JET with its ITER like wall, where no glow discharges were necessary throughout the whole campaign and very reliably breakdown could 
be achieved after disruptions even with massive gas injection for their mitigation [8]. The long term fuel retention was reduced by more than a factor of 5 as demonstrated in gas balance as well as in post mortem analyses.

Whereas in the initial unboronised $\mathrm{W}$ discharges low-Z impurities (carbon, oxygen) were still abundant, they were strongly suppressed after the first boronisations. As a consequence the divertor plasma temperatures and the power loads in the divertor increased strongly making the routine use of radiative cooling in high power discharges indispensable. By using nitrogen as cooling gas combined with a feedback control acting on the divertor electron temperature a very robust scenario was developed, also providing further improvement of the confinement. In recent discharges the validity of this approach could be demonstrated even at discharges with additional heating power above $20 \mathrm{MW}$, still providing good confinement $(\mathrm{H}=1)$, divertor power loads around $5 \mathrm{MWm}^{-2}$ and divertor temperatures below $10 \mathrm{eV}$.

ELM mitigation by pellet ELM pacemaking could be demonstrated, combining the beneficial effect of reducing the deposited energy per ELM in the divertor with the increased edge transport necessary to keep the $\mathrm{W}$ density at the pedestal low. Recently, the use of magnetic perturbation coils for ELM mitigation turned out to be very successful in terms of the ELM power load reduction but also not having any detrimental effect on $\mathrm{W}$ influx and $\mathrm{W}$ concentration.

As a recipe to keep the central $\mathrm{W}$ concentration sufficiently low, central (wave) heating is well established. In NBI dominated H-mode discharges a minimum gas fuelling has to be applied in addition, to reduce the $\mathrm{W}$ erosion and to diminish the $\mathrm{W}$ penetration. After the upgrade of the available ECRH power to $4 \mathrm{MW}$, low density type-I ELMy H-mode discharges could be re-established with pure ECRH, without being hampered by too high central $\mathrm{W}$ radiation.

Amongst the issues left is the reduced operational range of the ICRH system, due to the strong induced $\mathrm{W}$ sources at surfaces magnetically connected to the antennas. In order to test optimisation criteria provided by antenna codes, the ICRH limiter geometry was changed, which resulted in the predicted moderate reduction of the $\mathrm{W}$ source. In order to bridge the period until the new antennas will be available, 
the poloidal limiters of two antennas were boron coated, to allow unhindered use of ICRH without introducing $\mathrm{C}$ surfaces or other new materials. The observed substantial reduction of the incremental W content during ICRH operation makes it again a valuable tool for providing central heating and demonstrates that in the case of ASDEX Upgrade the antenna limiters are the main source of W. 


\section{References}

[1] V. Philipps, Journal of Nuclear Materials 415, S2 (2011).

[2] R. Neu, ASDEX Upgrade Team, EU PWI Taskforce, and JET EFDA Contributors, Plasma Physics and Controlled Fusion 53, 124040 (2011).

[3] R. Neu, V. Rohde, A. Geier, K. Krieger, H. Maier, D. Bolshukin, A. Kallenbach, R. Pugno, K. Schmidtmann, M. Zarrabian, and ASDEX Upgrade Team, Journal of Nuclear Materials 290-293, 206 (2001).

[4] R. Neu, K. Asmussen, K. Krieger, A. Thoma, H.-S. Bosch, S. Deschka, R. Dux, W. Engelhardt, C. García-Rosales, O. Gruber, A. Herrmann, A. Kallenbach, M. Kaufmann, V. Mertens, F. Ryter, V. Rohde, J. Roth, M. Sokoll, A. Stäbler, W. Suttrop, M. Weinlich, H. Zohm, M. Alexander, G. Becker, K. Behler, K. Behringer, R. Behrisch, A. Bergmann, M. Bessenrodt-Weberpals, M. Brambilla, H. Brinkschulte, K. Büchl, A. Carlson, R. Chodura, D. Coster, L. Cupido, H. J. de Blank, S. De Peña Hempel, R. Drube, H.-U. Fahrbach, J.-H. Feist, W. Feneberg, S. Fiedler, P. Franzen, J. C. Fuchs, G. Fußmann, J. Gafert, O. Gehre, J. Gernhardt, G. Haas, G. Herppich, W. Herrmann, S. Hirsch, M. Hoek, F. Hoenen, F. Hofmeister, H. Hohenöcker, D. Jacobi, W. Junker, O. Kardaun, T. Kass, H. Kollotzek, W. Köppendörfer, B. Kurzan, K. Lackner, P. T. Lang, R. S. Lang, M. Laux, L. L. Lengyel, F. Leuterer, M. E. Manso, M. Maraschek, K.-F. Mast, P. McCarthy, D. Meisel, R. Merkel, H. W. Müller, M. Münich, H. Murmann, B. Napiontek, G. Neu, J. Neuhauser, M. Niethammer, J.-M. Noterdaeme, E. Pasch, G. Pautasso, A. G. Peeters, G. Pereverzev, C. S. Pitcher, W. Poschenrieder, G. Raupp, K. Reinmüller, R. Riedl, H. Röhr, H. Salzmann, W. Sandmann, H.-B. Schilling, D. Schlögl, H. Schneider, R. Schneider, W. Schneider, G. Schramm, J. Schweinzer, B. D. Scott, U. Seidel, F. Serra, E. Speth, A. Silva, K.-H. Steuer, J. Stober, B. Streibl, W. Treutterer, M. Troppmann, N. Tsois, M. Ulrich, P. Varela, H. Verbeek, P. Verplancke, O. Vollmer, H. Wedler, U. Wenzel, F. Wesner, R. Wolf, R. Wunderlich, D. Zasche, T. Zehetbauer, and H.-P. Zehrfeld, Plasma Physics and Controlled Fusion 38, A165 (1996).

[5] K. Krieger, H. Maier, R. Neu, and ASDEX Upgrade Team, Journal of Nuclear 
Materials 266-269, 207 (1999).

[6] R. Neu, C. Hopf, A. Kallenbach, T. Pütterich, R. Dux, H. Greuner, O. Gruber, A. Herrmann, K. Krieger, H. Maier, V. Rohde, and ASDEX Upgrade Team, Journal of Nuclear Materials 367-370, 1497 (2007).

[7] G. Matthews, M. Beurskens, S. Brezinsek, M. Groth, E. Joffrin, A. Loving, M. Kear, M.-L. Mayoral, R. Neu, P. Prior, V. Riccardo, F. Rimini, M. Rubel, G. Sips, E. Villedieu, P. de Vries, M. Watkins, and EFDA-JET Contributors, Physica Scripta T145, 014001 (2011).

[8] G. Matthews, EFDA-JET Contributors, and ASDEX Upgrade Team, Review Talk, this conference, subm. to Jour. Nucl. Mater. (2012).

[9] C. Ruset, E. Grigore, H. Maier, R. Neu, X. Li, H. Dong, R. Mitteau, and X. Courtois, Physica Scripta T128, 171 (2007).

[10] R. Neu, V. Bobkov, R. Dux, J. C. Fuchs, O. Gruber, A. Herrmann, A. Kallenbach, H. Maier, M. Mayer, T. Pütterich, V. Rohde, A. C. C. Sips, J. Stober, K. Sugiyama, and ASDEX Upgrade Team, Physica Scripta T138, 014038 (6pp) (2009).

[11] A. Herrmann, R. Drube, T. Lunt, P. de Marné, and ASDEX Upgrade Team, Fusion Engineering and Design 86, 530 (2011).

[12] A. Kallenbach, R. Dux, M. Mayer, R. Neu, T. Pütterich, V. Bobkov, J. C. Fuchs, T. Eich, L. Giannone, O. Gruber, A. Herrmann, L. D. Horton, C. F. Maggi, H. Meister, H. W. Müller, V. Rohde, A. Sips, A. Stäbler, J. Stober, and ASDEX Upgrade Team, Nuclear Fusion 49, 045007 (2009).

[13] A. Herrmann, H. Greuner, J. C. Fuchs, P. de Marne, R. Neu, and A. U. Team, Physica Scripta T138, 014059 (4pp) (2009).

[14] F. Ryter, H.-U. Fahrbach, A. Gude, R. Neu, V. Rohde, J. Stober, and ASDEX Upgrade Team, Plasma Physics and Controlled Fusion 44, A407 (2002).

[15] Y. R. Martin, T. Takizuka, and the ITPA CDBM H-mode Threshold Database Working Group, Journal of Physics: Conference Series 123, 012033 (2008). 
[16] V. Rohde, M. Mayer, V. Mertens, R. Neu, K. Sugiyama, and ASDEX Upgrade Team, Nuclear Fusion 49, 085031 (9pp) (2009).

[17] K. Sugiyama, M. Mayer, V. Rohde, M. Balden, T. Durbeck, A. Herrmann, S. Lindig, A. Wiltner, H. Müller, R. Neu, and the ASDEX Upgrade team, Nuclear Fusion 50, 035001 (8pp) (2010).

[18] J. Roth, E. Tsitrone, A. Loarte, T. Loarer, G. Counsell, R. Neu, V. Philipps, S. Brezinsek, M. Lehnen, P. Coad, C. Grisolia, K. Schmid, K. Krieger, A. Kallenbach, B. Lipschultz, R. Doerner, R. Causey, V. Alimov, W. Shui, O. Ogorodnikova, A. Kirschner, G. Federici, A. Kukushkin, EFDA PWI Task Forceand ITER PWI Team, Fusion for Energy, and ITPA SOL/DIV, J. Nucl. Mater. 390-391, 1 (2009).

[19] B. Lipschultz et al., An Assessment of the Current Data Affecting Tritium Retention and its Use to Project Towards T Retention in ITER, Rep. PSFC/RR-10-4, Plasma Science and Fusion Center, MIT, Cambridge, USA, 2010.

[20] M. Mayer, V. Rohde, K. Sugiyama, J. L. Chen, X. Gong, C. Hopf, J. Likonen, S. Lindig, R. Neu, G. Ramos, E. Vainonen-Ahlgren, A. Wiltner, and ASDEX Upgrade Team, Journal of Nuclear Materials 390-391, 538 (2009).

[21] J. Roth and K. Schmid, presented at the 13th PFMC workshop, I-16, submitted to Physica Scripta (2011).

[22] K. Sugiyama, K. Krieger, M. Mayer, S. Lindig, M. Balden, T. Dürbeck, and ASDEX Upgrade team, Physica Scripta 2011, 014033 (2011).

[23] M. Balden et al., Oral, this conference, subm. to Jour. Nucl. Mater. (2012).

[24] E. Tsitrone, B. Pégourié, Y. Marandet, J. Artaud, C. Brosset, J. Bucalossi, Y. Corre, T. Dittmar, E. Gauthier, P. Languille, F. Linez, T. Loarer, C. Martin, P. Roubin, A. Kallenbach, K. Krieger, M. Mayer, R. Neu, V. Rohde, J. Roth, M. Rubel, S. Brezinsek, A. Kirschner, A. Kreter, A. Litnovsky, V. Philipps, P. Wienhold, J. Likonen, P. Coad, B. Lipschultz, and R. Doerner, Journal of Nuclear Materials 415, S735 (2011).

[25] V. Rohde, V. Mertens, A. Scarabosio, and ASDEX Upgrade Team, Journal of Nuclear Materials 390-391, 474 (2009). 
[26] V. Rohde, V. Mertens, R. Neu, , and ASDEX Upgrade Team, Dynamic wall loads measured by gas balance technique in all tungsten ASDEX Upgrade, in Proc. of the 23rd IAEA Fusion Energy Conference, Daejon, Korea Rep. of, volume IAEA-CN-180, pp. EXD/P3-28, Vienna, 2010, IAEA.

[27] K. Schmid, T. Schwarz-Selinger, W. Jacob, R. Dux, and ASDEX Upgrade Team, Nuclear Fusion 47, 984 (2007).

[28] R. Neu, R. Dux, A. Kallenbach, B. Kurzan, C. F. Maggi, R. Pugno, T. Pütterich, G. Tardini, and ASDEX Upgrade Team, Influence of the ${ }^{4} \mathrm{He}$ Concentration on H-mode Confinement and Transport in ASDEX Upgrade, in Europhysics Conference Abstracts (CD-ROM, Proc. of the 35th EPS Conference on Plasma Physics, Hersonissos, Crete, 2008), edited by P. Lalousis and S. Moustaizis, volume 32D, pp. P-4.039, Geneva, 2008, EPS.

[29] R. Neu, M. Balden, V. Bobkov, R. Dux, O. Gruber, A. Herrmann, A. Kallenbach, M. Kaufmann, C. F. Maggi, H. Maier, H. W. Müller, T. Pütterich, R. Pugno, V. Rohde, A. C. C. Sips, J. Stober, W. Suttrop, C. Angioni, C. V. Atanasiu, W. Becker, K. Behler, K. Behringer, A. Bergmann, T. Bertoncelli, R. Bilato, A. Bottino, M. Brambilla, F. Braun, A. Buhler, A. Chankin, G. Conway, D. P. Coster, P. de Marné, S. Dietrich, K. Dimova, R. Drube, T. Eich, K. Engelhardt, H.-U. Fahrbach, U. Fantz, L. Fattorini, J. Fink, R. Fischer, A. Flaws, P. Franzen, J. C. Fuchs, K. Gál, M. García Muñoz, M. Gemisic-Adamov, L. Giannone, S. Gori, S. da Graca, H. Greuner, A. Gude, S. Günter, G. Haas, J. Harhausen, B. Heinemann, N. Hicks, J. Hobirk, D. Holtum, C. Hopf, L. Horton, M. Huart, V. Igochine, S. Kálvin, O. Kardaun, M. Kick, G. Kocsis, H. Kollotzek, C. Konz, K. Krieger, T. Kurki-Suonio, B. Kurzan, K. Lackner, P. T. Lang, P. Lauber, M. Laux, J. Likonen, L. Liu, A. Lohs, K. Mank, A. Manini, M.-E. Manso, M. Maraschek, P. Martin, Y. Martin, M. Mayer, P. McCarthy, K. McCormick, H. Meister, F. Meo, P. Merkel, R. Merkel, V. Mertens, F. Merz, H. Meyer, M. Mlynek, F. Monaco, H. Murmann, G. Neu, J. Neuhauser, B. Nold, J.-M. Noterdaeme, G. Pautasso, G. Pereverzev, E. Poli, M. Püschel, G. Raupp, M. Reich, B. Reiter, T. Ribeiro, R. Riedl, J. Roth, M. Rott, F. Ryter, W. Sandmann, J. Santos, K. Sassenberg, A. Scarabosio, G. Schall, J. Schirmer, A. Schmid, W. Schneider, G. Schramm, R. Schrittwieser, W. Schustereder, J. Schweinzer, S. Schweizer, B. Scott, 
U. Seidel, F. Serra, M. Sertoli, A. Sigalov, A. Silva, E. Speth, A. Stäbler, K.-H. Steuer, E. Strumberger, G. Tardini, C. Tichmann, W. Treutterer, C. Tröster, L. Urso, E. Vainonen-Ahlgren, P. Varela, L. Vermare, D. Wagner, M. Wischmeier, E. Wolfrum, E. Würsching, D. Yadikin, Q. Yu, D. Zasche, T. Zehetbauer, M. Zilker, and H. Zohm, Plasma Physics and Controlled Fusion 49, B59 (2007).

[30] A. Kallenbach, R. Dux, V. Mertens, O. Gruber, G. Haas, M. Kaufmann, W. Poschenrieder, F. Ryter, H. Zohm, M. Alexander, K. Behringer, M. BessenrodtWeberpals, H.-S. Bosch, K. Büchl, A. R. Field, J. C. Fuchs, O. Gehre, A. Herrmann, S. Hirsch, W. Köppendörfer, K. Lackner, K. F. Mast, G. Neu, J. Neuhauser, S. De Peña Hempel, G. Raupp, K. Schönmann, A. Stäbler, K.-H. Steuer, O. Vollmer, M. Weinlich, W. P. West, T. Zehetbauer, and ASDEX Upgrade Team, Nuclear Fusion 35, 1231 (1995).

[31] K. Schmid, A. Manhard, C. Linsmeier, A. Wiltner, T. Schwarz-Selinger, W. Jacob, and S. Mändl, Nucl. Fusion 50, 025006 (2010).

[32] A. Kallenbach, R. Dux, J. C. Fuchs, R. Fischer, B. Geiger, L. Giannone, A. Herrmann, T. Lunt, V. Mertens, R. McDermott, R. Neu, T. Pütterich, S. Rathgeber, V. Rohde, K. Schmid, J. Schweinzer, W. Treutterer, and ASDEX Upgrade Team, Plasma Physics and Controlled Fusion 52, 055002 (2010).

[33] D. Neuwirth, V. Rohde, T. Schwarz-Selinger, and ASDEX Upgrade Team, accepted for publication in Plasma Phys. Control. Fusion (2012).

[34] R. Dux, V. Bobkov, A. Herrmann, A. Janzer, A. Kallenbach, R. Neu, M. Mayer, H. W. Müller, R. Pugno, T. Pütterich, V. Rohde, A. C. C. Sips, and ASDEX Upgrade Team, Journal of Nuclear Materials 390-391, 858 (2009).

[35] A. Thoma, K. Asmussen, R. Dux, K. Krieger, A. Herrmann, B. Napiontek, R. Neu, J. Steinbrink, M. Weinlich, U. Wenzel, and ASDEX Upgrade Team, Plasma Physics and Controlled Fusion 39, 1487 (1997).

[36] B. Lipschultz, D. Pappas, B. LaBombard, J. Rice, D. Smith, and S. Wukitch, Nucl. Fusion 41, 585 (2001). 
[37] V. Bobkov, F. Braun, R. Dux, A. Herrmann, L. Giannone, A. Kallenbach, A. Krivska, H. Müller, R. Neu, J.-M. Noterdaeme, T. Pütterich, V. Rohde, J. Schweinzer, A. Sips, I. Zammuto, and A. U. Team, Nuclear Fusion 50, 035004 (11pp) (2010).

[38] V. Bobkov, F. Braun, L. Colas, R. Dux, H. Faugel, L. Giannone, A. Herrmann, A. Kallenbach, H. Müller, R. Neu, J.-M. Noterdaeme, T. Pütterich, G. Siegl, E. Wolfrum, and ASDEX Upgrade Team, Journal of Nuclear Materials 415, S1005 (2011).

[39] R. Dux, Fusion Science and Technology 44, 708 (2003).

[40] J. Rapp, M. Tokar, L. Könen, H. Koslowski, G. Bertschinger, M. Brix, H. Claassen, R. Jaspers, A. Krämer-Flecken, K. Ohya, V. Philipps, A. Pospieszczyk, U. Samm, T. Tanabe, G. Telesca, B. Unterberg, and G. Van Oost, Plasma Phys. Control. Fusion 39, 1615 (1997).

[41] R. Dux, A. Janzer, T. Pütterich, and ASDEX Upgrade Team, Nuclear Fusion 51, 053002 (2011).

[42] A. Kallenbach, R. Neu, R. Dux, H.-U. Fahrbach, J. C. Fuchs, L. Giannone, O. Gruber, A. Herrmann, P. T. Lang, B. Lipschultz, C. F. Maggi, J. Neuhauser, V. Philipps, T. Pütterich, V. Rohde, J. Roth, G. Sergienko, A. Sips, and ASDEX Upgrade Team, Plasma Physics and Controlled Fusion 47, B207 (2005).

[43] T. Pütterich, R. Neu, R. Dux, A. D. Whiteford, M. G. O’Mullane, and ASDEX Upgrade Team, Plasma Physics and Controlled Fusion 50, 085016 (2008).

[44] K. Krieger, T. Lunt, R. Dux, A. Janzer, A. Kallenbach, H. Müller, R. Neu, T. Pütterich, V. Rohde, and ASDEX Upgrade Team, Journal of Nuclear Materials 415, S297 (2011).

[45] J. Coenen et al., Invited Talk, this conference, subm. to Jour. Nucl. Mater. (2012).

[46] T. Lunt, Y. Feng, K. Krieger, R. Neu, H. W. Müller, E. Wolfrum, M. Willensdorfer, M. Wischmeier, and ASDEX Upgrade team, Plasma Physics and Controlled Fusion 53, 125010 (2011).

[47] A. Geier, H. Maier, R. Neu, K. Krieger, and ASDEX Upgrade Team, Plasma Physics and Controlled Fusion 44, 2091 (2002). 
[48] R. Neu, R. Dux, A. Kallenbach, T. Pütterich, M. Balden, J. C. Fuchs, A. Herrmann, C. F. Maggi, M. O’Mullane, R. Pugno, I. Radivojevic, V. Rohde, A. C. C. Sips, W. Suttrop, A. Whiteford, and ASDEX Upgrade Team, Nuclear Fusion 45, 209 (2005).

[49] R. Dux, A. G. Peeters, A. Gude, A. Kallenbach, R. Neu, and ASDEX Upgrade Team, Nuclear Fusion 39, 1509 (1999).

[50] R. Neu, R. Dux, A. Geier, A. Kallenbach, R. Pugno, V. Rohde, D. Bolshukhin, J. C. Fuchs, O. Gehre, O. Gruber, J. Hobirk, M. Kaufmann, K. Krieger, M. Laux, C. Maggi, H. Murmann, J. Neuhauser, F. Ryter, A. C. C. Sips, A. Stäbler, J. Stober, W. Suttrop, H. Zohm, and ASDEX Upgrade Team, Plasma Physics and Controlled Fusion 44, 811 (2002).

[51] R. Neu, R. Dux, A. Geier, H. Greuner, K. Krieger, H. Maier, R. Pugno, V. Rohde, S. W. Yoon, and ASDEX Upgrade Team, Journal of Nuclear Materials 313-316, 116 (2003).

[52] O. Gruber, A. C. C. Sips, R. Dux, T. Eich, J. C. Fuchs, A. Herrmann, A. Kallenbach, C. F. Maggi, R. Neu, T. Pütterich, J. Schweinzer, J. Stober, and ASDEX Upgrde Team, Nuclear Fusion 49, 115014 (2009).

[53] R. Dux, R. Neu, A. G. Peeters, G. Pereverzev, A. Mück, F. Ryter, J. Stober, and ASDEX Upgrade Team, Plasma Physics and Controlled Fusion 45, 1815 (2003).

[54] M. Sertoli, C. Angioni, R. Dux, R. Neu, T. Pütterich, V. Igochine, and ASDEX Upgrade Team, Plasma Physics and Controlled Fusion 53, 035024 (2011).

[55] A. Kallenbach, M. Balden, R. Dux, T. Eich, C. Giroud, A. Huber, G. Maddison, M. Mayer, K. McCormick, R. Neu, T. Petrie, T. Pütterich, J. Rapp, M. Reinke, K. Schmid, J. Schweinzer, S. Wolfe, ASDEX Upgrade Team, DIII-D Team, Alcator Team, and JET-EFDA Contributors, Journal of Nuclear Materials 415, S19 (2011).

[56] J. Schweinzer, A. Sips, G. Tardini, P. Schneider, R. Fischer, J. Fuchs, O. Gruber, J. Hobirk, A. Kallenbach, R. McDermott, R. Neu, T. Pütterich, S. Rathgeber, J. Stober, J. Vicente, and ASDEX Upgrade Team, Nuclear Fusion 51, 113003 (2011). 
[57] H. Höhnle, J. Stober, A. Herrmann, W. Kasparek, F. Leuterer, F. Monaco, R. Neu, D. Schmid-Lorch, H. Schüz, J. Schweinzer, U. Stroth, D. Wagner, S. Vorbrugg, E. Wolfrum, and ASDEX Upgrade Team, Nuclear Fusion 51, 083013 (2011).

[58] P. T. Lang, A. Kallenbach, J. Bucalossi, G. D. Conway, A. Degeling, R. Dux, T. Eich, L. Fattorini, O. Gruber, S. Günter, A. Herrmann, J. Hobirk, L. D. Horton, S. Kalvin, G. Kocsis, J. Lister, M. E. Manso, M. Maraschek, Y. Martin, P. J. McCarthy, V. Mertens, R. Neu, J. Neuhauser, I. Nunes, T. Pütterich, V. Rozhansky, R. Schneider, W. Schneider, I. Senichenkov, A. C. C. Sips, W. Suttrop, W. Treutterer, I. Veselova, H. Zohm, and ASDEX Upgrade Team, Nuclear Fusion 45, 502 (2005).

[59] T. E. Evans, R. A. Moyer, J. G. Watkins, T. H. Osborne, P. R. Thomas, M. Becoulet, J. A. Boedo, E. J. Doyle, M. E. Fenstermacher, K. H. Finken, R. J. Groebner, M. Groth, J. H. Harris, G. L. Jackson, R. J. La Haye, C. J. Lasnier, S. Masuzaki, N. Ohyabu, D. G. Pretty, H. Reimerdes, T. L. Rhodes, D. L. Rudakov, M. J. Schaffer, M. R. Wade, G. Wang, W. P. West, and L. Zeng, Nuclear Fusion 45, 595 (2005).

[60] Y. Liang, H. Koslowski, P. Thomas, E. Nardon, et al., Phys. Rev. Letters 98, 265004 (2007).

[61] W. Suttrop, T. Eich, J. C. Fuchs, S. Günter, A. Janzer, A. Herrmann, A. Kallenbach, P. T. Lang, T. Lunt, M. Maraschek, R. M. McDermott, A. Mlynek, T. Pütterich, M. Rott, T. Vierle, E. Wolfrum, Q. Yu, I. Zammuto, H. Zohm, and ASDEX Upgrade Team, Phys. Rev. Lett. 106, 225004 (2011).

[62] W. Suttrop, L. Barrera, A. Herrmann, R. M. McDermott, T. Eich, R. Fischer, B. Kurzan, P. T. Lang, A. Mlynek, T. Pütterich, S. K. Rathgeber, M. Rott, T. Vierle, E. Viezzer, M. Willensdorfer, E. Wolfrum, I. Zammuto, and ASDEX Upgrade Team, Plasma Physics and Controlled Fusion 53, 124014 (2011).

[63] P. Lang, W. Suttrop, E. Belonohy, M. Bernert, R. McDermott, R. Fischer, J. Hobirk, O. Kardaun, G. Kocsis, B. Kurzan, M. Maraschek, P. de Marne, A. Mlynek, P. Schneider, J. Schweinzer, J. Stober, T. Szepesi, K. Thomsen, W. Treutterer, E. Wolfrum, and ASDEX Upgrade Team, Nuclear Fusion 52, 023017 (2012).

[64] A. Kallenbach, V. Bobkov, F. Braun, A. Herrmann, H. Höhnle, R. McDermott, R. Neu, 
J. Noterdaeme, T. Pütterich, J. Schweinzer, J. Stober, E. Strumberger, W. Suttrop, D. Wagner, and H. Zohm, Plasma Science, IEEE Transactions on 40, 605 (2012).

[65] A. Herrmann, H. Greuner, N. Jaksic, B. Böswirth, H. Maier, R. Neu, S. Vorbrugg, and ASDEX Upgrade team, Physica Scripta 2011, 014068 (2011).

[66] A. Herrmann, H. Greuner, N. Jaksic, B. Böswirth, F. Reimold, A. Scarabosio, S. Vorbrugg, M. Wischmeier, and ASDEX Upgrade team, to be presented at the 27th Symposium on Fusion Technology (SOFT) (24 - 28 Sep 2012, Liège, Belgium) .

[67] R. Dux, V. Bobkov, N. Fedorczak, K. Iraschko, A. Kallenbach, R. Neu, T. Pütterich, V. Rohde, and ASDEX Upgrade Team, Journal of Nuclear Materials 363-365, 112 (2007). 


\section{Figure captions}

Fig. 1. Photo of the interior of ASDEX Upgrade before closing for the 2012 campaign. The implementation of the magnetic perturbation coils on passive stabiliser loop provides a smooth transition to the baffle of the lower divertor. One of the newly installed poloidal guard limiters at the ICRH antenna can be identified on the left side by its matt grey appearance.

Fig. 2. Evolution of the L-H threshold compared with the ITER H-mode power threshold scaling [15] (left scale). The data span the period from 1999 - 2012 and at the bottom of the graphics the fraction of the $\mathrm{W}$ coverage is given (blue right scale). The vertical lines delimit the different campaigns.

Fig. 3. Parameters of the pedestal top in unfuelled $I_{p}=1 \mathrm{MA}, B_{t}=2.4-2.5 \mathrm{~T}$ discharges. The values taken during the campaign in 2005 (red dots, mixed C and W PFCs) were heated predominantly by NBI with additional 3 MW of ICRH. In the discharges performed in 2008 (green squares, full W wall) 1.5 MW of ECRH was used instead ICRH.

Fig. 4. Scan of puffing rates in similar discharges $\left(I_{p}=1 \mathrm{MA}, P_{N B I}=5 \mathrm{MW}, P_{E C R H} \leq 0.9\right.$ $\mathrm{MW})$. The puffing rates are given in black, the resulting pump fluxes are given in different colours. Depending on the puffing level the wall saturation (puff rate $\approx$ pump flux) is reached later. The upper right insert shows that the saturation is always reached at approximately the same amount of injected gas $\left(4.5-4.8 \cdot 10^{22}\right.$ at, blue bars $)$. The gas retained after reaching the saturation is also similar $\left(1.1-1.6 \cdot 10^{22}\right.$ at, violet bars).

Fig. 5. Divertor parameters during the type III ELMy H-Mode discharge \#25679 with $I_{p}=1.2 \mathrm{MA}, B_{t}=2.5 \mathrm{~T}, P_{\text {aux }}=8.5 \mathrm{MW}$. The parameters from top to bottom are: $T_{e}$ divertor electron temperature, $P_{\text {peak }}$ peak power load, $D_{\alpha}$ intensity of the deuterium Balmer spectral

line, NII radiance $\mathrm{N}^{1+}$ spectral line, and the $\mathrm{W}$ influx from spectroscopic measurements 
Fig. 6. Behaviour of the $\mathrm{W}$ concentration in an discharge $\left(I_{p}=0.8 \mathrm{MA}, B_{t}=2.0 \mathrm{~T}\right)$ with ICRH at $30 \mathrm{MHz}$ using the antenna pair with boron coating (ICRF12, pink) and the one with tungsten coating (ICRF34, green) in sequence. The parameters from top to bottom are: $P_{N B I}, P_{I C R H}$ neutral beam injection and ion cyclotron frequency heating power, $W_{m h d}$ stored energy, $n_{e}^{\text {centre }}, n_{e}^{\text {edge }}$ central and edge line averaged density and $c_{W}$ tungsten concentration. The red dashed line marks $c_{W}$ without ICRH.

Fig. 7. Schematic view of the main transport processes relevant for the build-up of the W content in the plasma.

Fig. 8. Plasma parameters of discharges \#22895,898,900,901 $\left(I_{p}=1 \mathrm{MA}, B_{t}=2.5 \mathrm{~T}\right)$ in AUG with all W PFCs (after [67]). The discharges were performed in a similar way except the feed forward gas puffing level was varied in the second half (starting at 2.5s) from $10^{21} \mathrm{~s}^{-1}$ to $10^{22} \mathrm{~s}^{-1}$. Note, from $t=2.8 \mathrm{~s}$ onward another $2.5 \mathrm{MW}$ of NBI heating were added (in total: NBI: 7.5 MW, ECRH: 1.3 MW). The parameters from top to bottom are: $W_{m h d}$ stored energy, $n_{W} \mathrm{~W}$ density, $n_{C} \mathrm{C}$ density, $\Phi_{\text {lim }} \mathrm{W}$ limiter source and $\Delta t_{E L M}$ inverse ELM frequency. $R_{\text {out }}$ sketches a shift of the plasma column towards the low field side guard limiters.

Fig. 9. Discharge \#27327 ( $\left.I_{p}=1.2 \mathrm{MA}, B_{t}=2.5 \mathrm{~T}\right)$ with nitrogen radiative cooling at the highest heating power applied so far in $\operatorname{AUG}(P / R=14)$ with good confinement and very moderate peak power load in the divertor. The total radiation power at $3.3 \mathrm{~s}$ reached about 10.7 MW in the main chamber and 9.1 MW in the divertor, while the divertor plasma temperature was controlled to $\approx 11 \mathrm{eV}$. 


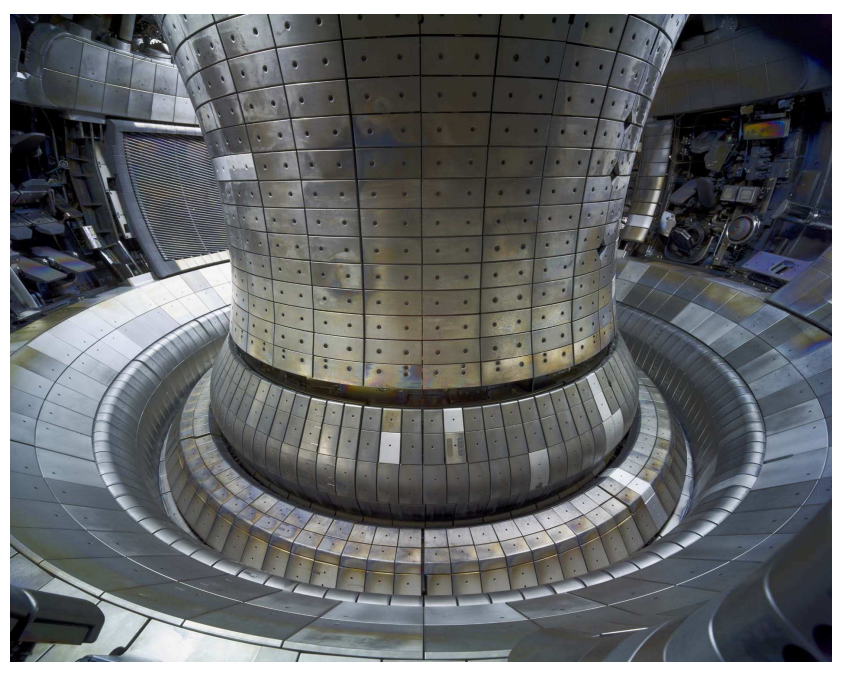

Fig.1 


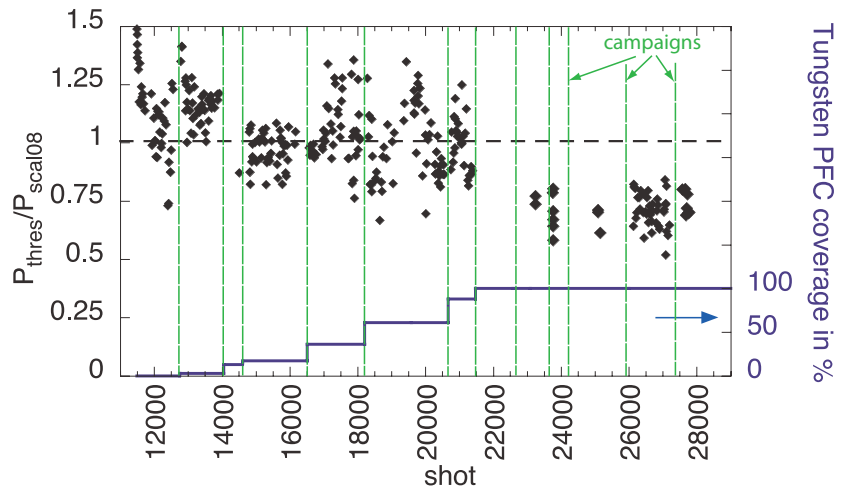

Fig.2 

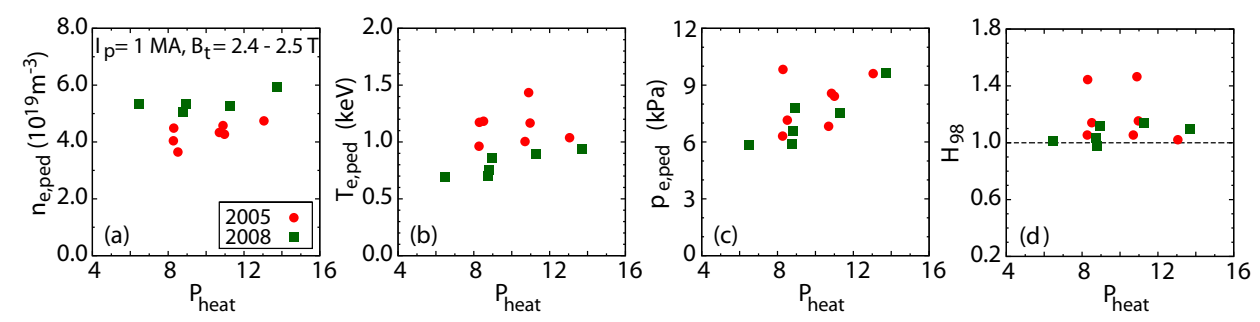

Fig. 3 


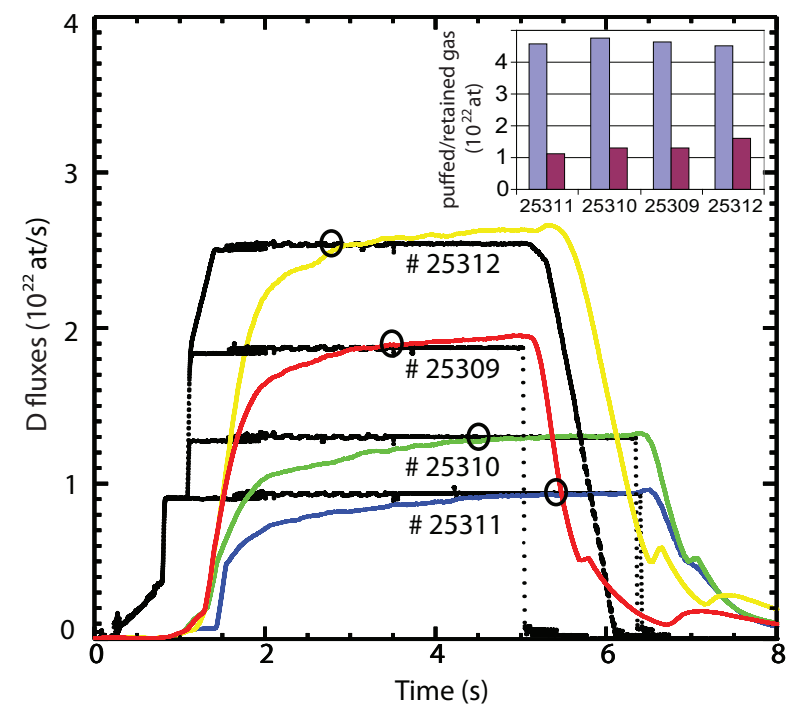

Fig.4 


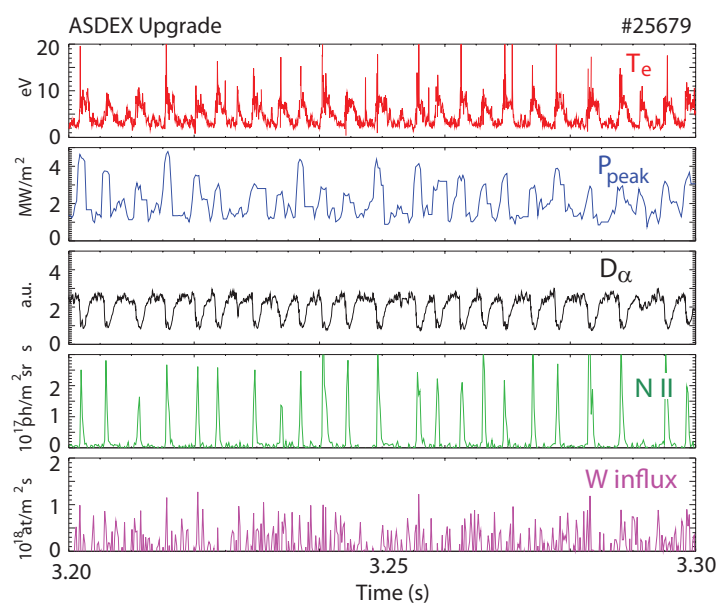

Fig.5 


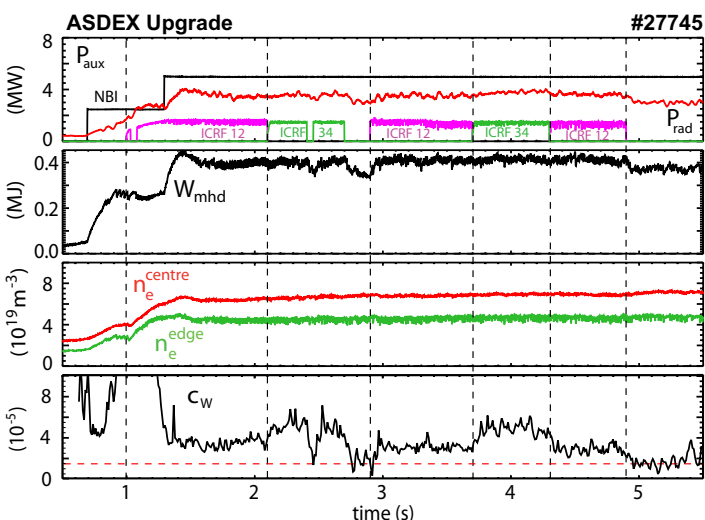

Fig.6 


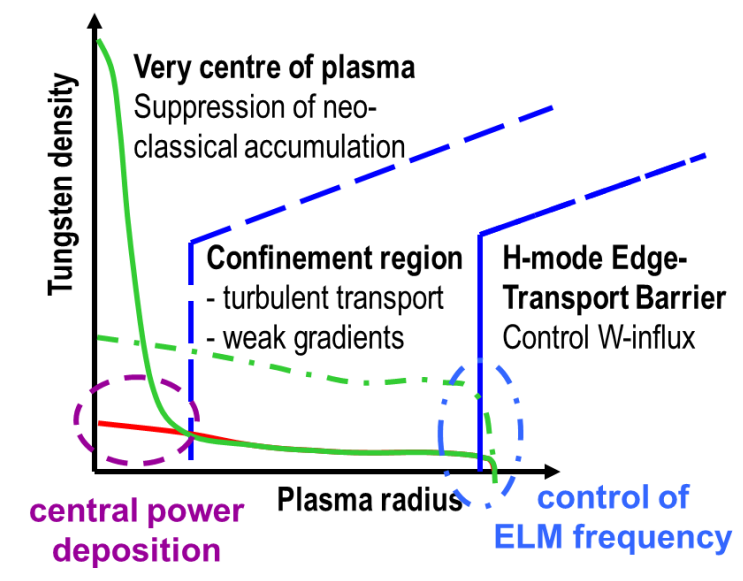

Fig.7 


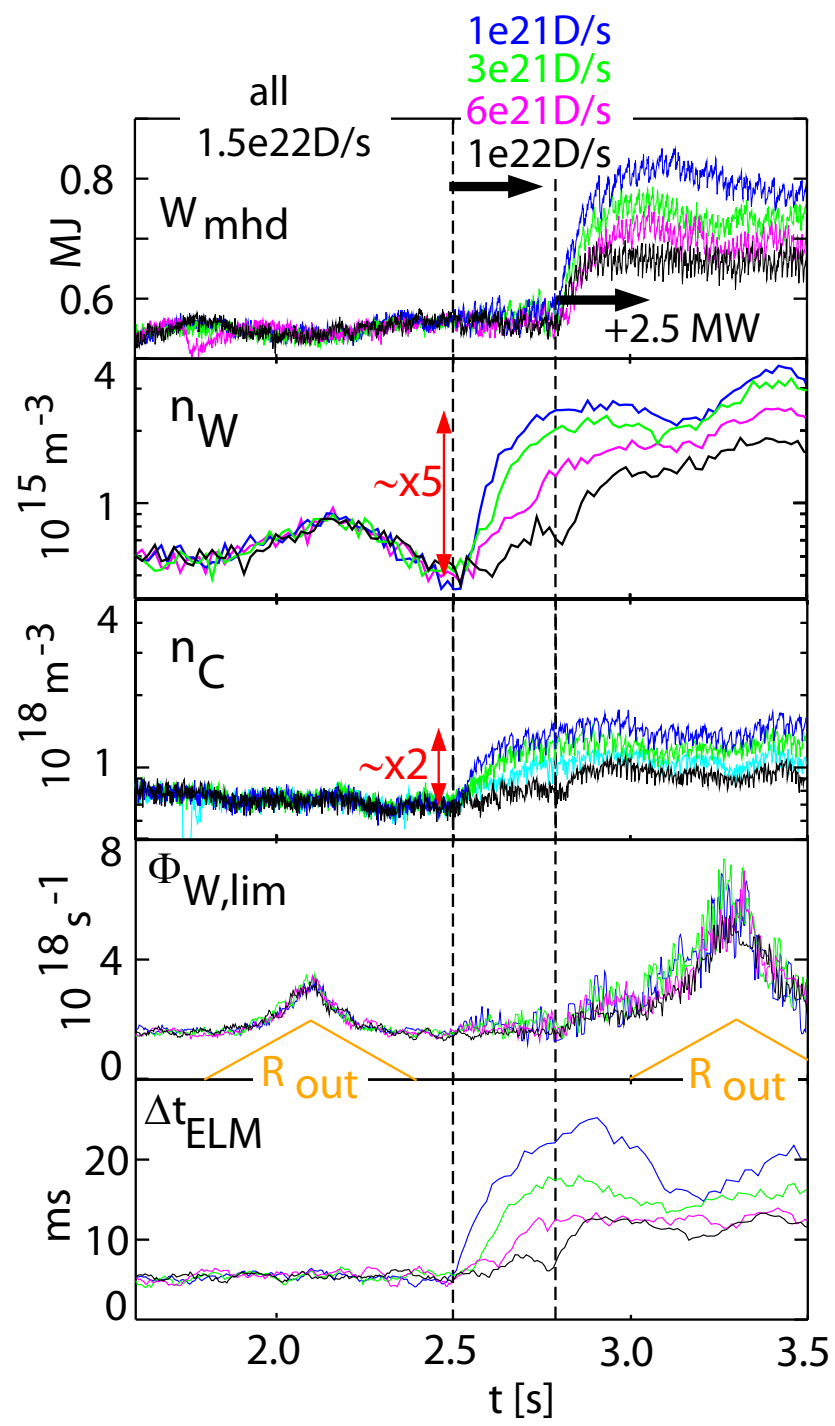

Fig.8 


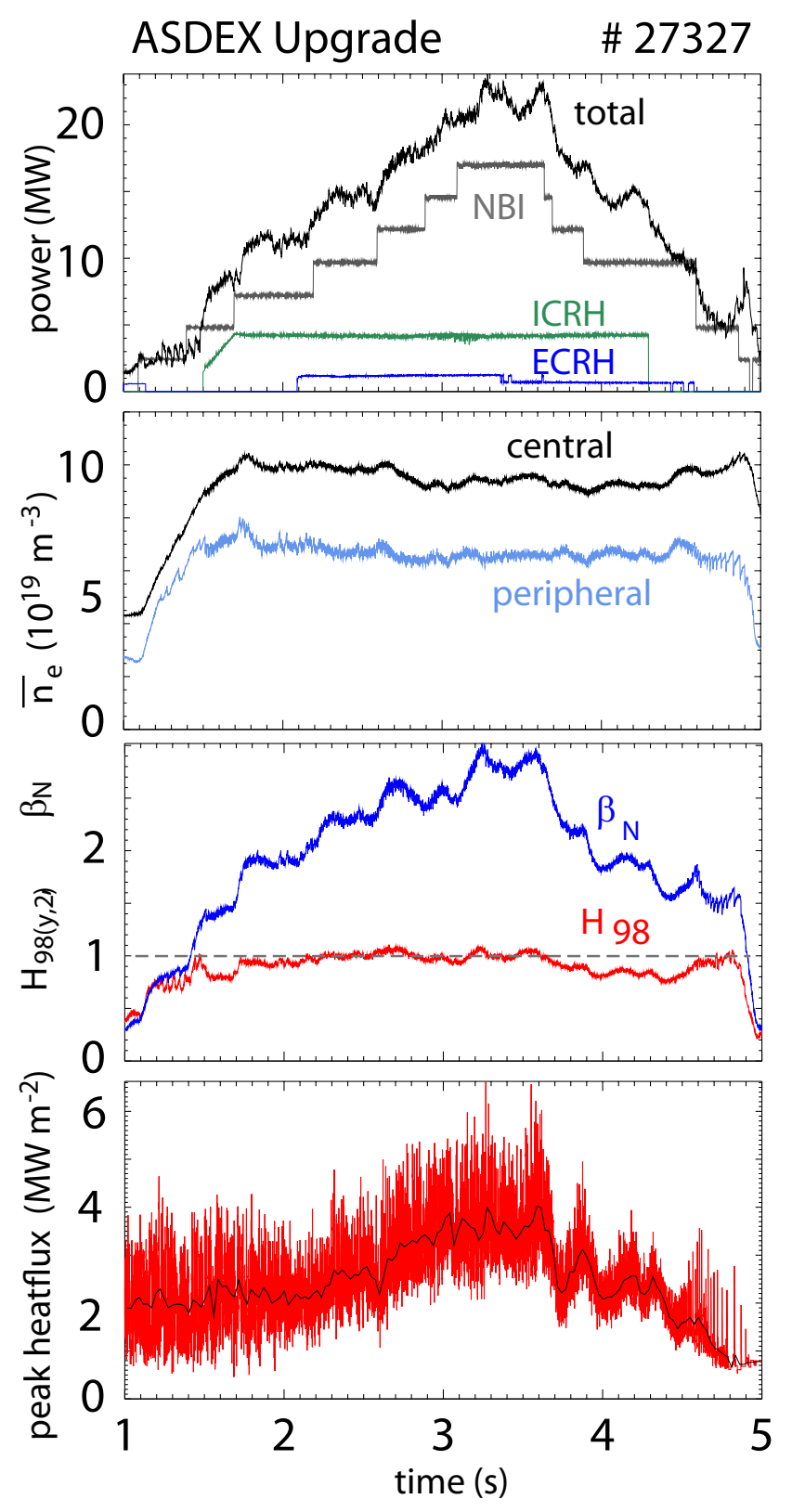

Fig.9 